\title{
Analysis of the Practice of Network Technology in Electronic Information Technology
}

\author{
Qi Zang ${ }^{1}$, Haisheng Song ${ }^{1, a}$ \\ ${ }^{1}$ College of Physics and Electronic Engineering, Northwest Normal University, Lanzhou, 730070, \\ China \\ a763380829@qq.com
}

\begin{abstract}
Keywords: network technology; electronic information technology; practice analysis
Abstract. With the rapid development of science and technology, electronic information technology has been highly valued in various fields and widely used in modern society. It not only brings a lot of convenience to modern life, work and study, but also, to a certain extent, affects the modern way of thinking. As the core technology in electronic information technology, network technology and information technology complement and promote each other, and boost the steady development of information society in China jointly. In this paper, the practice of network technology in electronic information technology will be analyzed.
\end{abstract}

\section{Introduction}

In recent years, electronic information technology has already been blended in every aspect of our life and played a crucial role in modern life. Especially under the background of rapid development of network technology, the combination between network technology and electronic information technology has become an inevitable trend in the development of modern society. During actual application, we must analyze both the characteristics of network technology and electronic information technology, maximize their application effect, further enhance the speed and quality of information acquisition and transmission and provide a lot of convenience and application value for the development of modern enterprises.

\section{Brief Introduction to Electronic Information Technology}

Electronic information technology is a highly comprehensive discipline, mainly based on electron carriers, which studies the whole process, from the generation, transmission, storage and display, etc. of information using electronic carriers. For details, see Table 1:

Table 1 Analysis of the Whole Process of Electronic Information Technology

\begin{tabular}{|c|c|c|}
\hline $\begin{array}{c}\text { Whole Process of } \\
\text { Electronic } \\
\text { Information Technology }\end{array}$ & $\begin{array}{c}\text { Relevant } \\
\text { Department }\end{array}$ & Post \\
\hline Design & Product design & $\begin{array}{c}\text { Electronic product designer } \\
\text { Electronic product tester } \\
\text { Electronic wire pedal designer }\end{array}$ \\
\hline Production & Production & $\begin{array}{c}\text { Electronic component purchaser } \\
\text { Production process administer } \\
\text { Quality control manager }\end{array}$ \\
\hline Sales & Marketing & $\begin{array}{c}\text { Information manager } \\
\text { Product sales engineer } \\
\text { Sales personnel }\end{array}$ \\
\hline Service & Technical support & $\begin{array}{c}\text { Technical assistant } \\
\text { Project construction manager } \\
\text { After-sales service engineer }\end{array}$ \\
\hline
\end{tabular}

With the constant improvement of science and technology, types of electronic information technology also tend to be diversified. Electronic technology, photoelectron technology, 
microelectronics technology, communication technology and other forms emerged, played a vital role in the development of modern society and provide a lot of convenience for the launch of economic business in modern enterprises. In colleges and universities, electronic information technology belongs to the field of engineering. From the angle of engineering, electronic information technology has high applicability and practicality. Especially with the rapid development of network technology, electronic information technology is increasingly dependent on and closely related to network technology. It has become a kind of important engineering technology in the construction of modern society [1].

\section{Brief Introduction to Network Technology}

Network technology is a new type of computer technology. It can integrate scattered resources on the Internet organically, maximize internal resource sharing and collaboration, help enhance the overall ability of modern people to obtain information resources and provide more reliable data as a reference for the development of modern society. Many resources are designed in network technology. Network forms constituted by different types of resources also vary a lot. For details, see Table 2:

Table 2 Analysis of Network Technology Resources and Network

\begin{tabular}{|l|l|}
\hline & High-performance computer \\
& Memory resources \\
& Data resources \\
& Information resources \\
& Knowledge resources \\
& Expert resources \\
& Large database \\
\hline \multirow{3}{*}{ Network Composition } & Regional network \\
& Intranets of enterprises and public \\
& institutions \\
& LAN \\
& Home network \\
\hline
\end{tabular}

In recent years, with the rapid development of science and technology, the research and development of network technology has also received high attention, the usability of network technology has been maximized and more convenience has been provided for the development of modern society. The rational use of network technology can effectively maximize resource sharing. It is conducive to the centralized processing and efficient transmission of information, further enhance the equilibrium of network load [2] and provide users with more high-quality integrated services.

\section{Analysis of the practice of network technology in electronic information technology}

To improve the speed of information transmission

The rational use of network technology in electronic information technology can effectively increase the speed of information transmission and convey all types of information to people in need in an easier and faster way. For example, if a certain highway collapses and causes a serious traffic jam, many netizens can learn about the actual situation of highway jam in such forms as radio, network TV and social media, evade this highway as far as possible, choose a more convenient and safe travelling route and alleviate the traffic jam at the site of the accident effectively. Moreover, relevant departments can also understand road conditions at the site instantly through advanced network technology, take appropriate measures to remedy and restore the highway in the shortest time possible [3]. Thus it can be seen that it is very necessary to use network technology in electronic information technology rationally, to give full play to the actual role of electronic information technology and increase the speed of information transmission.

To achieve the sharing of information resources 
The application of network technology in electronic information technology can achieve the sharing of information resources effectively, transmit a large number of information resources, ensure speed and quality in the whole process of information transmission and further enhance the utilization of information resources. In Tangshan earthquake, for example, in the absence of advanced network technology and electronic information technology, plenty of information at the site of accident can't be spread in time. Also, it was very difficult for external information to come in. People can't grasp details about the site of earthquake accurately and timely. Most information was given by survivors, which, to a certain extent, increased losses caused by the earthquake. In the 2008 Wenchuan earthquake, the use of network technology and electronic information technology tended to be mature. The government was able to grasp actual situation at the site of earthquake instantly and develop a more perfect rescue plan, according to the information fed back. At the same time, the actual situation at the site of Wenchuan earthquake was also released to the world in real time, so that international aid organizations and other countries can rescue Wenchuan area. From here, the rational use of network technology, to a certain extent, maximizes resource sharing, ensures that people can learn about relevant information accurately and timely and further enhances the utilization of information resources [4].

To guarantee the safe operation of information

The rational use of network technology in electronic information technology provides a basic guarantee for the safe operation of information. During actual application, electronic information technology is susceptible to external factors and often invaded by viruses and trojans, which seriously affects the normal use of electronic information technology, causes losses, damages and theft, etc. of information resources and endangers the safe operation of information resources. The combination between network technology and electronic information technology can backup important data in the system. Meanwhile, a defense system can be installed, to prevent the system from being interfered with by external factors when processing information and offer a safety guarantee to system information, using firewall and safety protection software, etc. in network technology [5] Fig. 1 shows safety protection between intranet and extranet.

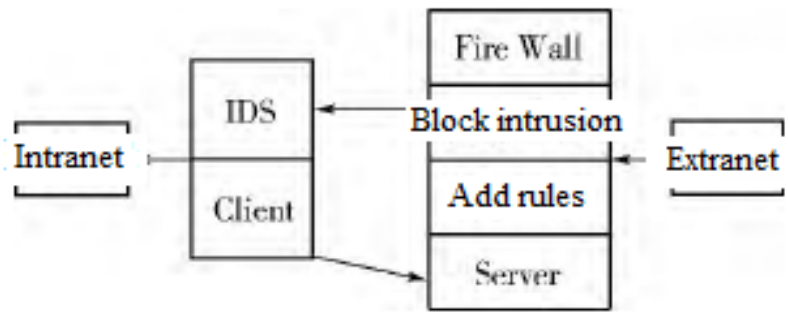

Fig. 1 The Safety Protection between Intranet and Extranet

\section{Conclusion}

From the above analysis, with the constant improvement of network technology, applying network technology to electronic information technology has become a main trend in the development of modern society. Diversified network technology boosts the steady development of electronic information technology and offers a lot of help to the research and upgrade of electronic information equipment. At present, information interaction in electronic information technology in China still needs to draw support from network technology. It can effectively improve the speed of information transmission, achieve the sharing of information resources and provide a basic guarantee for the safe operation of information.

\section{References}

[1]Jarrahi M H. A structurational analysis of how course management systems are used in practice[J]. Behaviour \& Information Technology, 2010, 29(3):257-275. 
[2]Sánchez-Franco M J, Roldán J L. The influence of familiarity, trust and norms of reciprocity on an experienced sense of community: an empirical analysis based on social online services[J]. Behaviour \& Information Technology, 2015, 34(4):392-412.

[3]Dhavle A A, Yang Y, Rupp M T, et al. Analysis of Prescribers' Notes in Electronic Prescriptions in Ambulatory Practice.[J]. Jama Internal Medicine, 2016.

[4]González-Teruel A, González-Alcaide G, Barrios M, et al. Mapping recent information behavior research: an analysis of co-authorship and co-citation networks[J]. Scientometrics, 2015, 103(2):687-705.

[5]Winther T, Wilhite $H$. An analysis of the household energy rebound effect from a practice perspective: spatial and temporal dimensions[J]. Energy Efficiency, 2015, 8(3):595-607. 